\title{
Síndrome de Burnout em Agentes Comunitários de Saúde e Estratégias de Enfrentamento
}

Burnout Syndrome in Community Health Agents and Coping Strategies

\author{
Stela Heloisa Telles \\ Psicóloga. Mestranda da Escola de Enfermagem de Ribeirão \\ Preto/USP-SP. \\ Endereço: Av. XV de Novembro N8 648, Bairro Estados Unidos, CEP \\ 38015-300, Uberaba, MG, Brasil. \\ E-mail: stelatellesळgmail.com \\ Ana Maria Carvalho Pimenta \\ Psicóloga. Professora e Doutora do Departamento de Enfermagem \\ Psiquiátrica e Ciências Humanas da Escola de Enfermagem de \\ Ribeirão Preto/USP-SP. \\ Endereço: Av. Bandeirantes, 3900, CEP 14040-902, Ribeirão Preto, \\ São Paulo, SP, Brasil. \\ E-mail: anacarøeerp.usp.br
}

\section{Resumo}

Esta investigação propõe-se a verificar a ocorrência da Síndrome de Burnout em Agentes Comunitários de Saúde, visto que esses profissionais trabalham diretamente no cuidado a outras pessoas - característica prevalente em tal Síndrome -, bem como as estratégias de enfrentamento utilizadas. Optou-se pelo método descritivo, transversal e quantitativo. Foram aplicados o questionário Maslach Burnout Inventory (MBI) e a Escala Modos de Enfrentamento de Problemas (EMEP). A amostra constituiu-se por 8o ACS, escolhidos aleatoriamente entre aqueles admitidos há pelo menos dois anos no serviço público municipal. Verificou-se que se trata de uma amostra predominantemente do sexo feminino (93,75\%), com filhos (68,75\%), na faixa etária de 20 a 30 anos (35\%) e com companheiro fixo (60\%). A renda per capita de $38,75 \%$ é de menos de um salário mínimo; 53,04\% estão nesse trabalho há mais de seis anos e relatam ter vida sedentária. O MBI revela um sentimento de deterioração da percepção da própria competência dos profissionais e, também, falta de satisfação com o próprio trabalho. Eles demonstram estar emocionalmente esgotados e verifica-se o desenvolvimento incipiente de sentimentos e atitudes negativas, além de cinismo para com as pessoas por eles atendidas. O Modo de Enfrentamento mais utilizado são as estratégias focalizadas no problema, seguidas pela busca de práticas religiosas/pensamento fantasioso. Verificam-se indícios de sofrimento característicos da Síndrome de Burnout, com o esforço de buscar mecanismos que auxiliem no enfrentamento de problemas relacionados ao trabalho. Sugerem-se estratégias de acolhimento a esses profissionais, de forma a auxiliálos a lidar com o sofrimento no trabalho.

Palavras-chave: Estresse; Burnout; Saúde Ocupacional. 


\section{Abstract}

This research aims to verify the occurrence of the Burnout Syndrome in Community Health Agents (CHA). These professionals work directly in care delivery to other people, and this is a prevalent characteristic in this Syndrome. Another aim is to verify the coping strategies such professionals use. A descriptive, crosssectional and quantitative study was carried out. A questionnaire - the Maslach Burnout Inventory (MBI) - and the Ways of Coping Scale (WOCS) were administered. The sample consisted of 8o CHA, randomly chosen among professionals who had been working for at least two years in the municipal public service. The results show that the sample was predominantly female (93.75\%), with children (68.75\%), belonging to the age group 20-30 years old (35\%) and with a steady partner (6o\%). The per capita income of $38.75 \%$ is less than one minimum salary, 53.04\% have been working in this job for more than six years and lead a sedentary life. The MBI reveals a feeling of deterioration in the perception of these professionals' own competence and lack of satisfaction with their own work. They present emotional exhaustion, and the incipient development of negative attitudes and cynicism towards the people they deliver care to were noticed. The most used coping strategies are problem-focused ones, followed by the search for religious practices/fantastic thinking. Symptoms of suffering which are typical of the Burnout Syndrome, as well as the effort to seek for mechanisms that help to cope with work-related problems, were observed. Strategies to welcome these professionals are suggested so as to help them deal with suffering at work.

Keywords: Stress; Burnout; Occupational Health.

\section{Introdução}

Durante os anos 2000 e 2001, atuei como psicóloga no Banco de Leite Humano realizando a capacitação de Agentes Comunitários de Saúde (ACS) para o atendimento a gestantes e nutrizes quanto ao aleitamento materno. Durante essas capacitações, foi possível perceber, por meio da verbalização de suas experiências, o envolvimento emocional destes nas questões da família assistida. Assim, o presente estudo teve como propósito identificar a provável ocorrência da Síndrome de Burnout entre os ACS das Equipes de Saúde da Família de uma cidade do interior de Minas Gerais e descrever as estratégias e esforços cognitivos e comportamentais desenvolvidos para lidar com situações de estresse.

O exercício da profissão de ACS resulta em uma relação com o usuário que, por vezes, apresenta-se permeada de ambiguidades, e os conflitos decorrentes são fenômenos característicos dessa profissão, podendo levar os profissionais a sentimentos de ansiedade e até incapacidade de apresentar soluções viáveis ao problema vivido pelos usuários.

Há décadas, diversos grupos religiosos e organizações não governamentais treinam agentes de saúde. A atitude de ser solidário, de prestar ajuda às pessoas sempre foi reconhecida como uma ação valorosa, mas não se pode desconsiderar que tal ação tem os seus custos emocionais.

O ACS é uma pessoa da própria comunidade, com vida igual à do grupo por ele assistido. 0 que o diferencia dos demais é o fato de deter um pouco mais de informações para orientar as famílias a cuidar de sua própria saúde e também da saúde da comunidade. Ele atende aos moradores de cada casa em todas as questões relacionadas à saúde: identifica problemas, orienta, encaminha e acompanha a realização dos procedimentos necessários à proteção, promoção, recuperação/reabilitação da saúde das pessoas daquela comunidade.

Segundo Silva e Dalmaso (2002), na execução do seu trabalho, o ACS se defronta com uma série de situações para as quais nem mesmo outros profissionais da área da saúde têm um saber sistematizado de forma explícita e, tampouco, os instrumentos adequados de trabalho e gerência. Estas ações compreendem desde a forma de abordagem da família, o contato direto e imediato com situações de vida precária que determinam 
as condições de saúde, até o posicionamento frente à desigualdade social e à busca da cidadania.

Esses profissionais e a população acompanhada criam vínculos de corresponsabilidade, o que facilita a identificação e o atendimento aos problemas de saúde da comunidade. A atenção está centrada na família, entendida e percebida a partir do seu ambiente físico e social, o que vem possibilitando às equipes uma compreensão ampliada do processo saúde/doença e da necessidade de intervenções que vão além de práticas curativas (Brasil, 2002).

A Portaria 648/2006 (Brasil, 2006), que aprova a política nacional de atenção básica, estabelecendo a revisão de diretrizes e normas para a organização da atenção básica para o Programa Saúde da Família (PSF), e o Programa Agentes Comunitários de Saúde (PACS) descrevem as atividades a serem desenvolvidas pelo ACS na execução do seu trabalho. Verifica-se que esses profissionais deverão:

[...] realizar a escuta qualificada das necessidades dos usuários em todas as ações, proporcionando atendimento humanizado e viabilizando o estabelecimento do vínculo [...]; desenvolver ações que busquem a integração entre a equipe de saúde e a população adscrita [...]; estar em contato permanente com as famílias desenvolvendo ações educativas [...]; desenvolver atividades de promoção da sáude [...] por meio de visitas domiciliares [...]; acompanhar, por meio de visitas domiciliares, todas as famílias e indivíduos [...] e realizar visitas periódicas para monitoramento das situações de risco à família (grifo da autora).

Percebe-se que as atribuições e ações desenvolvidas pelo ACS estão diretamente relacionadas à questão do cuidado, buscando sempre o bem-estar do outro. A atividade requer que sejam seguidas algumas regras determinadas por uma técnica, por um cronograma preestabelecido, pelo planejamento, pelas normas e determinações dos superiores, por questões administrativas. Cuidar envolve tanto o desempenho de técnicas quanto o trato com as emoções e afetos envolvidos nas relações entre profissionais e usuários dos serviços de saúde. Para Codo e Vasques-Menezes (2000, p. 53) "ao cuidar de outrem, o cuidador se transforma, na mesma medida em que transfere para o outro parte de si mesmo e vê neste seu trabalho realizado".
Para Silva (2000), a partir do momento em que o trabalhador está inserido em um contexto organizacional, atuam sobre ele diferentes variáveis modificando seu estado pessoal, seu trabalho, sua saúde e suas relações sociais. Psicologicamente, o trabalho provoca diferentes graus de motivação e satisfação, conforme enfatiza Kanaane (1994). O desgaste físico e emocional a que o indivíduo está submetido neste ambiente e na execução de suas tarefas é bastante significativo na determinação de transtornos mentais e comportamentais, incluindo os transtornos de humor, ansiedade, depressão, fobias, distúrbios psicossomáticos e Burnout.

Dejours (1988, p. 43) ressalta que, do confronto entre o indivíduo com uma história de vida singular e a organização do trabalho (divisão do trabalho, conteúdo da tarefa, organização hierárquica, responsabilidades), que possui uma "injunção despersonalizante", surge o sofrimento mental. Não havendo condições de adequação do trabalho à sua própria personalidade, este aumenta sua carga psíquica, o que resultará em sofrimento. Ainda segundo este autor, quando o trabalhador ingressa em uma organização, ele já encontra um conjunto de tarefas que devem ser cumpridas, com seus objetivos e meios para realizá-las determinados, devendo a ele somente executá-lo.

Verifica-se, portanto, que o trabalho ocupa um lugar muito importante na dinâmica do investimento afetivo das pessoas.

Para Maslach e Leiter (1999, p. 13), a alegria do sucesso e a emoção da conquista estão cada vez mais distantes do trabalhador, acarretando em uma diminuição do compromisso e da dedicação ao trabalho. As pessoas estão ficando descrentes, cultivando uma distância "segura" e tentando não se envolver demais e, junto a isso, tem-se que "o local de trabalho é um terreno fértil para o desgaste físico e emocional” (Maslach e Leiter, 1999, p. 39). Para adaptar-se às novas relações, o trabalhador produz uma resposta emocional visando diminuir o desajuste percebido, com isso, poderá apresentar sentimentos de inutilidade, ansiedade e até mesmo depressão. Nesse processo, o sujeito busca adaptar-se de modo a proteger-se das tensões, desenvolvendo, dessa forma, estratégias de enfrentamento.

Vivenciando o estresse proveniente do trabalho de forma crônica, o trabalhador precisa desenvolver atitudes que lhe permitam continuar em atividade: uma 
delas é o não investimento de energia nas tarefas a serem desenvolvidas. Isso leva à destituição de sentido do trabalho e seus resultados passam a não mais importar. Tais sinais são indicativos de que este trabalhador está vivenciando a Síndrome de Burnout.

A partir de 1970, as ciências da saúde lançaram mão deste termo para descrever o que acontece com o trabalhador. Segundo Benevides-Pereira (2003b, p. 14), a partir do artigo intitulado "Staff Burnout", escrito em 1974 pelo psiquiatra Herbert J. Freudenberger, os estudos sobre Burnout se intensificam. 0 termo foi empregado como uma metáfora para designar o sentimento de profissionais que trabalhavam com pacientes dependentes de substâncias psicoativas e que sofriam, sentiam-se derrotados, estavam exaustos e não conseguiam alcançar os objetivos propostos. Burnout foi definido como um estado de esgotamento ou exaustão resultante de grande dedicação e esforço no trabalho, sendo que a pessoa desconsidera até as suas próprias necessidades.

Trata-se de uma síndrome (conjunto de sintomas) e, para Benevides-Pereira (2003a, p. 14), vai além do estresse, pois está intimamente relacionada com o trabalho e, para fazer frente à sintomatologia física e psicológica experimentada, o profissional acaba por desenvolver despersonalização, passa a ter um contato frio e impessoal, até mesmo cínico e irônico com seus clientes.

No Brasil, somente com a publicação do Decreto ${ }^{\circ}$ 3.048 de 6 de maio de 1999 (Brasil, 1999), que dispõe sobre a Regulamentação da Previdência Social, em seu anexo II - Agentes Patogênicos causadores de Doenças Profissionais -, é que a Síndrome de Burnout foi reconhecida como uma enfermidade pertencente à categoria de saúde do trabalhador e diretamente vinculada à atividade laborativa. É classificada como um transtorno mental e do comportamento relacionado ao trabalho e enunciada no CID-1o no código: Z 73.0 - "Síndrome de Burn-Out", "Síndrome de Esgotamento Profissional".

O estabelecimento de consenso entre os diferentes autores quanto à definição e aos modelos explicativos referentes à Síndrome de Burnout constitui-se, ainda, em uma grande dificuldade. Na presente exposição, adotar-se-á a perspectiva psicossocial, que aborda a Síndrome de Burnout como um processo, em que os aspectos do contexto de trabalho e interpessoais contribuem para seu desenvolvimento.
Para Codo (2002, p. 238), a Síndrome de Burnout é "uma síndrome através da qual o trabalhador perde o sentido de sua relação com o trabalho [...] afeta, principalmente, profissionais da área de educação e saúde quando em contato direto com seus usuários".

É uma síndrome multidimensional e inclui três componentes: Exaustão emocional, Despersonalização e Redução da realização pessoal (Maslasch e col., 2001; Benevides-Pereira, 2003a. p. 35). A dimensão Exaustão Emocional é caracterizada por um forte sentimento de tensão emocional, que produz uma sensação de esgotamento, de falta de energia e de recursos emocionais próprios para lidar com rotinas da prática profissional, representando a dimensão individual da síndrome. Despersonalização é o resultado do desenvolvimento de sentimentos e atitudes negativas, por vezes indiferentes e cínicas em torno daquelas pessoas que entram em contato direto com o profissional, que são sua demanda e objeto de trabalho. É um fator de proteção, mas pode representar um risco de desumanização, constituindo a dimensão interpessoal de Burnout. A terceira dimensão é a Redução da realização pessoal, em que o sujeito evidencia o sentimento de insatisfação para com o trabalho, sente-se incapaz, insuficiente, desmotivado e com baixa autoestima.

Quanto à incidência ou prevalência dos sintomas de Burnout, verifica-se que as ocupações assistenciais são as mais afetadas, pois estão fundamentadas na filosofia humanística, e a discrepância entre as expectativas e a realidade contribui para o nível de estresse desses profissionais (Alvarez e Fernandez, 1991). Outro fator que contribui é o tempo dedicado aos clientes, que nem sempre é pouco, e também o fato de estarem sempre vivenciando situações de muito sofrimento, gerando, com isso, uma relação interpessoal permeada por fortes sentimentos, como frustração, medo e tensão emocional.

Apesar da dificuldade de consenso quanto aos desencadeantes, verifica-se que há convergências nos estudos em apontar uma incidência elevada de tal síndrome entre profissionais de saúde (Amorim, 2002; Benevides-Pereira, 2003a, 2003b; Benevides-Pereira e Moreno-Jiménez, 2003; Gil-Monte e Peiró, 1997; Tamayo, 1997), professores (Codo, 2002; Silva e Barboza, 2003; Carlotto e Palazzo, 2006) e policiais (Gil-Monte e Peiró, 1997), caracterizando uma tendência de endemia, muito embora não ocorra exclusivamente com essas profissões. 
A excessiva identificação com o usuário e os conflitos interpessoais aumentam os sentimentos de "queimar-se/consumir-se", bem como o sentimento de culpa. Entretanto, agir tendo por base esses pensamentos não ajuda a lidar com o desgaste, pois "mente que desconfia de si mesma não pode inspirar o melhor na mente alheia" (Branden, 2002, p. 316). Assim, o indivíduo utiliza estratégias de enfrentamento como forma de aumentar a percepção de controle pessoal da situação estressora, e a escolha pelo sujeito depende de seu repertório interno e de experiências anteriores nas quais essas estratégias foram reforçadas (Savoia e col., 1996). Segundo Zakir (2003), as estratégias de enfrentamento fazem parte do desenvolvimento humano e de como este reage ao ambiente em que vive.

Portanto, enfrentamento refere-se aos "esforços cognitivos e comportamentais voltados para o manejo de exigências ou demandas internas ou externas, que são avaliadas como sobrecarga aos recursos pessoais do indivíduo" (Folkman e col., 1986, p. 571), o que o torna um processo dinâmico e multidimensional que visa manter o equilíbrio, amenizando os efeitos das situações estressantes.

Tendo como base as concepções sobre estresse e síndrome de Burnout, e considerando a categoria dos ACS, este trabalho propôs-se a investigar sinais indicativos da síndrome e estratégias de enfrentamento utilizadas no contexto da atuação profissional.

\section{Método}

O presente estudo foi desenvolvido em um município do interior de Minas Gerais, com perímetro urbano de $256 \mathrm{Km}^{2}$ (aproximadamente $2 \%$ do território) e população estimada pelo IBGE, para o ano de 2006, de 287.760 habitantes. No período de realização da pesquisa, a rede de saúde do município era composta por 12 unidades de internação hospitalar (11 privadas e 1 pública), 39 unidades ambulatoriais (34 públicas e 5 privadas), 25 unidades de apoio, diagnose e terapia (24 privadas e 1 pública) e, ainda, 41 ESF implantadas, sendo 37 na região urbana e 4 na rural.

O município apresentava 250 ACS admitidos no serviço público, quando da realização da pesquisa. Efetuou-se sorteio de 80 ACS, o que representava um terço da população geral, e era necessário, ainda, que estes apresentassem um tempo mínimo de dois anos de trabalho e que estivessem atuantes. Foi estabelecido esse número de participantes para compor a amostra do presente estudo em função do tempo de que a pesquisadora dispunha para percorrer cada equipe e abordá-los individualmente dentro do cronograma estabelecido para o cumprimento das atividades. Assim, foi estabelecida uma amostra por conveniência.

Para a realização da referida pesquisa, optou-se pelo método descritivo, transversal e quantitativo, por se tratar um método rápido, de baixo custo e objetivo na coleta de dados (Pereira, 1995), sendo o mais utilizado na epidemiologia atual (Almeida Filho e Rouquaryol, 1992).

Antes que fosse iniciada a elaboração do projeto de pesquisa, foi solicitada a autorização da Prefeitura Municipal (Secretaria Municipal de Saúde) para a sua realização. Obtida a autorização do setor responsável, o projeto foi encaminhado ao Comitê de Ética em Pesquisa da Escola de Enfermagem de Ribeirão Preto da Universidade de São Paulo, sendo aprovado em 21 de junho de 2006.

De posse dessa aprovação, novo contato com a Secretaria Municipal de Saúde foi feito para o início dos trabalhos. Foram enviados ofícios às chefias dos setores solicitando sua colaboração e o acesso aos ACS. Foram previamente agendados os horários com os Agentes, com apoio dos Coordenadores de cada Equipe de Saúde da Família, para aplicação dos instrumentos, que ocorreu no próprio local de trabalho da Equipe, em uma sala previamente designada para este fim, assegurando sempre o sigilo necessário aos trabalhos.

A pesquisa foi iniciada em julho de 2006, logo após a aprovação pelo Comitê de Ética em Pesquisa da Escola de Enfermagem de Ribeirão Preto da Universidade de São Paulo, sendo a coleta de dados encerrada em dezembro do mesmo ano, quando os ACS responderam ao questionário de caracterização, ao MBI e à EMEP - instrumentos utilizados no levantamento de tais dados.

No dia agendado para a coleta de dados, era realizada a apresentação da pesquisadora e, posteriormente, os ACS recebiam uma explicação dos objetivos da pesquisa, do modo de aplicação; eram informados de que os dados seriam tratados de forma sigilosa, que era assegurado o anonimato e que a participação seria voluntária e seu consentimento poderia ser retirado a qualquer momento, sem nenhuma penalidade. Todos os ACS sorteados concordaram e assinaram o Termo de 
Consentimento Livre e Esclarecido, conforme Resolução 196/96 do Conselho Nacional de Ética em Pesquisa (Brasil, 200o).

Iniciou-se a coleta de dados com a autoaplicação, com supervisão da pesquisadora, do Maslach Burnout Inventory (MBI), traduzido e adaptado para o português por Tamayo (1997), constando de 22 itens, distribuídos em três fatores: 1 - exaustão emocional (9 itens, $\alpha=0,88$ ); 2 - falta de realização pessoal no trabalho (8 itens, $\alpha=0,94$ ); e 3 - despersonalização ( 5 itens, $\alpha=0,65$ ). 0 cálculo dos escores dos indivíduos é realizado por meio da atribuição de valores relativos à frequência. 0 escore total bruto dos sujeitos é obtido por meio dos somatórios de cada item do inventário. O escore do sujeito em cada uma das dimensões (exaustão, realização pessoal e despersonalização) também é computado pelo somatório dos pontos dos itens relativos a cada uma das dimensões. Devido ao caráter multidimensional da síndrome, o MBI tem se mostrado como o mais adequado, sendo utilizado segundo a bibliografia consultada.

Em seguida, foi feita a autoaplicação, também com a supervisão da pesquisadora, da Escala Modos de Enfrentamento de Problemas (EMEP). Instrumento submetido à análise fatorial por Seidl e colaboradores (2001), composto de 45 itens, distribuídos em 4 fatores: 1 - enfrentamento focalizado no problema (18 itens, $a=0,84$ ), estratégias comportamentais que representam aproximação em relação ao estressor, voltadas para o seu manejo ou solução, bem como estratégias cognitivas direcionadas para a reavaliação e ressignificação do problema; 2 - enfrentamento focalizado na emoção (15 itens, $a=0,81$ ), estratégias cognitivas e comportamentais de esquiva e/ou negação, expressão de emoções negativas, pensamento fantasioso, autoculpa e/ou culpabilização de outros, com função paliativa ou de afastamento do problema; 3 - busca de suporte social ( 5 itens, $a=0,70$ ), procura de apoio social emocional ou instrumental para ajudar a lidar com o problema; 4 - busca de práticas religiosas ( 7 itens, $a=0,74$ ), pensamentos e comportamentos religiosos como modos de enfrentamento e manejo do estressor. As respostas serão dadas em escala Likert de 5 pontos (1 = "nunca faço isso"; 5 = "faço isso sempre"). Os escores serão obtidos pela média aritmética e, quanto mais altos, maior a frequência de utilização da estratégia de enfrentamento.
Após a aplicação do Inventário Síndrome de Burnout de Maslach (MBI) e da Escala Modos de Enfrentamento de Problemas (EMEP), realizou-se a aplicação de um questionário contendo perguntas referentes aos dados pessoais, situação e relacionamento profissional, condições de habitação, saúde pessoal, lazer, atividade física, situação familiar e socioeconômica.

\section{Resultados}

Verificou-se que 93,75\% dos ACS são do sexo feminino, nascidos no município (53,75\%), com faixa etária entre 20 e 40 anos (65\%), com 2 filhos (49,09\%) e com companheiro fixo (6o\%).,A maior frequência referente à renda per capita é de 1 a 1,9 salários - 42,50\%, ressaltando que o salário base de um ACS da cidade é R\$ 650,00 (o salário-mínimo do governo federal é R\$ 350,oo).

Dentre os sujeitos pesquisados, verificou-se que 53,04\% (35) atuavam há mais de seis anos no Programa de Saúde da Família, e são diversas as profissões desenvolvidas por estes antes de ingressarem nessa função. As que mais se destacaram foram: vendedores/balconistas/caixas (comércio), com 13,75\%; e diarista/faxineira/doméstica, com 12,50\%. Porém, 13,75\% não tinham nenhuma experiência de trabalho anterior, tendo ingressado no mercado de trabalho na função de ACS.

Com relação à distribuição percentual da atividade no tempo livre, frequência e tipo de atividade física e/ou esportiva da amostra pesquisada, 66,25\% dos ACS referiram não praticar atividade física e/ou esportiva sistematicamente. Entre os 33,75\% que praticavam alguma atividade, a que mais se destaca é a corrida/caminhada, com $23,75 \%$, sendo esta uma prática regular (33,75\%).

Questionados sobre o que pensavam a respeito do local de trabalho, $62,5 \%$ dos ACS o consideravam como bom; sentiam-se respeitados, valorizados e elogiados $67,5 \%$, entretanto, $52,5 \%$ relataram que sentiam que o local de trabalho não oferecia o conforto necessário às atividades realizadas, e 61,3\% disseram que não tinham dificuldades em sua relação com a Administração Municipal. Entretanto, dos 37,5\% que disseram ter alguma dificuldade, $16,7 \%$ queixaram-se do ambiente de trabalho.

Com relação à saúde, $75 \%$ relataram não apresentar problemas e, entre aqueles que referiram, $24 \%$ disseram apresentar problemas de depressão. Os ACS 
pesquisados não apresentavam deficiência física, e $75 \%$ não estavam sob tratamento médico. Entre aqueles que estavam em tratamento, $35 \%$ foram atendidos com problemas ligados ao psiquismo junto aos profissionais Psicólogo, Psiquiatra e/ou Neurologista. 73,7\% dos participantes não utilizavam medicamentos e $71,3 \%$ informaram nunca terem sido acometidos por problemas de saúde mais graves. Com relação ao uso de substâncias psicoativas, 71,2\% informaram não usálas. Entre aqueles que usavam, o cigarro se destacou, com $64,7 \%$ de usuários. Quanto à assistência médica utilizada, $87,5 \%$ utilizavam a assistência pública, 73,7\% assistência odontológica também pública e classificavam o atendimento como bom. De forma geral, classificaram as condições de saúde de suas famílias como boa $(62,5 \%)$.

Interrogados quanto ao desejo de se submeterem a programas de treinamento e/ou capacitação, $20 \%$ dos sujeitos manifestaram o desejo de se qualificarem na área de enfermagem - curso técnico de enfermagem, e $10 \%$ em informática, sendo estas as opções que apresentaram maior frequência.

Quanto aos pontos positivos descritos pelos ACS, $33,7 \%$ alegaram ser o tipo de trabalho que realizavam e $10 \%$ alegaram a possibilidade de gozar dias de feriados e folgas. Por sua vez, $17,5 \%$ relataram que não há ponto negativo no trabalho, seguidos de $15 \%$ que consideraram a instabilidade como sendo um desses pontos; $13,7 \%$ consideraram o salário baixo.

A partir da aplicação do questionário Maslach Burnout Inventory (MBI) para a investigação quanto à Síndrome de Burnout, obtiveram-se os resultados apresentados no quadro a seguir:

Quadro I - Resultados obtidos pelos ACS no Maslach Burnout Inventory (MBI) para avaliação da Síndrome de Burnout, 2006

\begin{tabular}{l|c}
\hline Fatores & Média \\
\hline Exaustão Emocional (EE) & 2,53 \\
\hline Despersonalização (DE) & 1,94 \\
\hline Redução da realização pessoal no trabalho (RP) & 4,15 \\
\hline
\end{tabular}

Assim, observou-se que os ACS apresentaram média 4,15 na dimensão Redução da realização pessoal no trabalho, índice mais elevado em relação às outras dimensões. A dimensão Exaustão Emocional vem logo a seguir, com média 2,53 e, por fim, a dimensão Despersonalização, com média 1,94.

Com relação à Escala Modos de Enfrentamento de Problemas - EMEP, obtiveram-se os resultados exibidos no Quadro 2:

\section{Quadro 2 - Resultados médios obtidos a partir da Escala Modos de Enfrentamento de Problemas pelo grupo de ACS, 2006}

\begin{tabular}{l|c|c|c}
\hline Fator - EMEP & Média Geral & Valor Mínimo & Valor Máximo \\
\hline Estratégias de enfrentamento focalizadas no problema & 3,93 & 2,50 & 4,89 \\
\hline Estratégias de enfrentamento focalizadas na emoção & 2,38 & 1,00 & 3,80 \\
\hline Busca de práticas religiosas/pensamento fantasioso & 3,44 & 1,29 & 4,71 \\
\hline Busca de suporte social & 3,38 & 1,40 & 5,20 \\
\hline
\end{tabular}

As estratégias mais utilizadas foram as focalizadas no problema (média = 3,93), seguidas pela busca de práticas religiosas/pensamento fantasioso (média =3,44), conforme mostra o quadro acima. Os valores mínimos e máximos indicam que há variações individuais no uso das estratégias, sendo essa variação maior para as estratégias relativas às práticas religiosas e à busca de suporte social.

\section{Discussão}

0 presente estudo trabalhou com uma amostra de 80 ACS de um município do interior de Minas Gerais, que responderam ao MBI - questionário para avaliação da ocorrência da Síndrome de Burnout - e à EMEP - Escala Modos de Enfrentamento de Problemas -, a fim de verificar a estratégias utilizadas ao lidarem com problemas. 
Não foi encontrado, na literatura, estudo semelhante relacionado à ocorrência da Síndrome de Burnout nessa categoria profissional. Entretanto, foram encontrados estudos relacionados à qualidade de vida desses profissionais, à ética no trabalho e educação, ao fazer profissional, ao crescimento e fortalecimento profissional (Camelo, 2002; Bezerra e col., 2005; Ferraz e Aerts, 2005; Kluthcovsky, 2005; Lunardelo, 2004; Silva e Dalmaso, 2002).

De acordo com os dados obtidos neste estudo, foi possível observar que o sexo feminino predominou entre a população pesquisada. Outros estudos mostram essa predominância, como enfatizado por Camelo (2002); Lunardelo (2004); Ferraz e Aerts (2005); Bezerra e colaboradores (2005) e Kluthcovsky (2005), trata-se de uma população jovem, com companheiro fixo e filhos; condições semelhantes foram reveladas pelos estudos anteriormente citados. Quanto ao tempo de trabalho, apresentavam uma média de mais de seis anos de atuação junto ao Programa de Saúde da Família, dado relevante, pois o tempo de permanência no Programa é importante para o entendimento do papel do ACS; o que também foi apresentado pelo estudo realizado por Ferraz e Aerts (2005), em que o tempo médio de trabalho era de mais de três anos.

Ser admitido como ACS representou, para alguns, a oportunidade de reingresso no mercado de trabalho; para outros, o reconhecimento e a remuneração do trabalho desenvolvido como voluntário na comunidade. Para aquelas pessoas que não tinham experiência de trabalho formal anteriormente, este foi o seu primeiro registro profissional e, por gostarem das atividades desenvolvidas, permaneceram na função. Portanto, os motivos que levaram essas pessoas a escolherem essa profissão são os mais diversos, entretanto, gostar do trabalho que executam e permanecer em atividade têm sido o ponto comum entre elas.

No que se refere à renda, é um emprego com uma remuneração "mínima", fator que é suplantado pelo prazer de realizar o trabalho, pois relataram sentirem-se respeitados e valorizados. Lunardelo (2004) apresentou, em estudo realizado com ACS do município de Ribeirão Preto, que os Agentes "priorizam a oportunidade de emprego visto a significativa situação de desemprego", não sendo o salário mencionado pelos mesmos.

Com relação à distribuição percentual da atividade no tempo livre, frequência e tipo de atividade física e/ ou esportiva da amostra pesquisada, verificou-se que a maior parte dos ACS não praticava atividade física e/ou esportiva sistematicamente, exceto aquela já realizada no desempenho de suas atividades laborais. Segundo Simões (2008), atualmente há um aumento significativo na incidência de doenças crônico-degenerativas na população em geral, devido ao sedentarismo; no entanto, a atividade física, por sua vez, proporciona benefícios, como prevenção de problemas cardiovasculares, combate à obesidade, promoção do bem-estar físico e maior integração social do indivíduo com seu meio. Tal aspecto também é relatado por Barbanti (2008), enfatizando a melhora da autoestima, do autoconceito, da imagem corporal, das funções cognitivas e de socialização; a diminuição do estresse e da ansiedade e a diminuição do consumo de medicamentos. Com isso, a forma como o trabalho é executado, ou seja, caminhadas regulares para a realização de visitas em cada domicílio, tem propiciado aos ACS o benefício de realizar uma atividade física.

A maioria dos ACS que participou do estudo relatou não ter problemas de saúde; situação semelhante foi encontrada por Kluthcovsky (2005), ao pesquisar a qualidade de vida dos Agentes Comunitários no interior do Paraná. Um dado importante é que, entre aqueles que estão realizando algum tratamento para a saúde, este é feito com profissionais das áreas relacionadas ao psiquismo - Psicólogo, Psiquiatra e/ou Neurologista. Sabendo que a Síndrome de Burnout está entre os transtornos mentais relacionados ao trabalho, percebese que há necessidade de um olhar diferenciado para a saúde mental desses ACS.

Quanto ao tempo de afastamento em virtude de licença médica, verificou-se que os ACS não vinham utilizando esse recurso para se ausentarem, permanecendo o menor tempo possível longe do trabalho, até porque relataram que o ponto positivo é o trabalho que realizam.

Buscando um maior envolvimento com o trabalho, manifestaram o desejo de se submeterem a programas de treinamento e/ou capacitação, a fim de se qualificarem na área de enfermagem - curso técnico. Segundo Silva e Dalmaso (2002), “a profissionalização dos agentes está ocorrendo em áreas que lidam com necessidades da população, como o campo da enfermagem...”. Essa possibilidade de obterem uma formação profissional, segundo a autora, correlaciona-se com o 
reconhecimento de seu trabalho e a execução de procedimentos técnicos específicos da área de enfermagem, ampliando ainda mais as ações a serem desenvolvidas por eles.

O presente estudo não teve a pretensão de investigar todos os aspectos envolvidos na Síndrome, portanto, optou-se por verificar sinais indicativos da síndrome e estratégias de enfrentamento utilizadas no contexto da atuação profissional, visto que as exigências impostas pelo exercício dessa atividade de trabalho comportam aspectos semelhantes àqueles envolvidos em outras profissões, que podem predispor o trabalhador ao desenvolvimento da síndrome.

Identificar o perfil dos ACS em Uberaba tornou possível conhecer um pouco desse universo profissional, fornecendo subsídios para a análise dos dados e, posteriormente, para auxiliar em estudos futuros quanto ao perfil dos profissionais de saúde que exercem essa função.

A partir da aplicação do Maslach Burnout Inventory (MBI) para a investigação quanto à Síndrome de Burnout, verificou-se, pelo índice de Exaustão Emocional, que os ACS estão iniciando um processo em que a percepção da própria competência para a realização do trabalho está sendo comprometida, pois demonstram estar emocionalmente esgotados. Esse esgotamento se justifica devido ao contato diário mantido com as pessoas que atendem, resultando, assim, em uma tensão emocional. Essa situação pode levar a uma avaliação negativa de si mesmo e, com isso, ocorrer uma perda de grande parte de sua autoestima.

Em menor escala, com a evolução da dimensão Despersonalização, que avalia os sentimentos, as atitudes negativas e o cinismo para com as pessoas destinatárias do trabalho, poderão substituir o vínculo afetivo pelo racional. Se não apoiados ainda nesta fase, poderão acentuar o sofrimento psíquico e afetivo; daí a importância do apoio e da criação de um espaço para compartilhar tais sentimentos.

A dimensão Redução da realização pessoal no trabalho avalia o sentimento de competência e satisfação com as realizações e os sucessos no trabalho, bem como as habilidades na sua execução e na relação com as pessoas atendidas.

0 resultado apresentado no MBI revela, portanto, um sentimento de deterioração da percepção da competência dos profissionais e sua falta de satisfação com o próprio trabalho. Eles demonstram estar emocionalmente esgotados e verifica-se o desenvolvimento incipiente de sentimentos, atitudes negativas e cinismo para com as pessoas por eles atendidas.

Estudo realizado com professores de escolas particulares de uma cidade da região metropolitana de Porto Alegre (Carlotto e Palazzo, 20o6) mostrou que a dimensão Exaustão emocional apresentou a maior média (2,30), seguida pela dimensão Redução da realização pessoal no trabalho $(1,63)$, sendo que o menor índice referiu-se à dimensão Despersonalização $(1,49)$. Corroborando com o exposto, tem-se o estudo realizado por Benevides-Pereira (2003a), com médicos do município de Maringá, que revelou um índice elevado para a dimensão Redução da realização pessoal no trabalho $(5,17)$, seguido da dimensão Exaustão emocional $(2,50)$ e, posteriormente, da dimensão Despersonalização $(1,20)$. Condição semelhante é apresentada em outro estudo (Benevides-Pereira, 2003a), desta vez com profissionais de enfermagem de três hospitais, sendo um público e dois privados: o resultado obtido na dimensão Redução da realização pessoal no trabalho $(4,78)$, seguido da dimensão Exaustão emocional $(2,15)$ e, posteriormente, da dimensão Despersonalização $(1,12)$.

Segundo Carlotto e Câmara (2008, p. 157) "não há um ponto de corte para a população brasileira, que permita classificar a síndrome em níveis (baixo médio, alto)[...] e sua caracterização específica é pouco conhecida, especialmente em uma sociedade onde as relações de trabalho são pautadas pela necessidade de sobrevivência".

Como aspecto positivo no desenvolvimento do trabalho, destaca-se a receptividade dos ACS, que aceitaram prontamente participar do estudo. Esse aspecto pode revelar a necessidade de esses trabalhadores terem um espaço em que possam ser ouvidos. Assim, uma intervenção psicológica visando o fortalecimento da rede de suporte social se constitui em uma proposta de trabalho a ser sugerida e posteriormente desenvolvida pela Prefeitura, a fim de amenizar os efeitos das situações estressantes.

Entretanto, é preciso esclarecer que não depende só de uma intervenção junto a esses trabalhadores de forma isolada, mas deve atingir a dinâmica de trabalho da organização, ou seja, da Prefeitura Municipal; é este o desafio que abrange esta proposta, pois deve focar o indivíduo e a organização como um todo. Percebe-se, 
portanto, a importância da prevenção no combate aos fatores deflagradores da Síndrome, o que envolve todo um estudo quanto às condições de trabalho a que esses profissionais estão submetidos.

Nesta pesquisa, com a aplicação do instrumento Escala Modo de Enfrentamento de Problemas, verificou-se que as estratégias de enfrentamento focalizadas no problema são as mais utilizadas. Por meio delas, a pessoa busca o manejo ou a modificação do problema ou situação causadora de estresse, visando controlar ou lidar com a ameaça, o dano ou o desafio; em geral, é uma estratégia ativa de aproximação em relação ao estressor, como solução de problemas e planejamento. Incluem também esforços ativos, eminentemente cognitivos, voltados para a reavaliação do problema (Seidl e col., 2001). Esta também foi a estratégia mais utilizada pelos sujeitos da pesquisa referente às estratégias de enfrentamento dos trabalhadores, desenvolvida por Santos e Chamon (2006), sendo que $85,8 \%$ destes faziam uso de tal estratégia.

Para Wai (2007, p. 115), em estudo realizado com ACS, verificou-se que estes utilizavam de estratégias que lhes possibilitassem interferir no problema, ou seja, naquilo que estivesse "causando tensão, nestas estratégias, incluem definir o problema, gerar soluções alternativas em termos de vantagens e desvantagens".

Quanto à busca de Práticas Religiosas/Pensamentos Fantasiosos, segunda categoria de estratégias mais utilizadas, é possível evidenciar uma postura de esquiva da situação estressora, no âmbito cognitivo. Em estudo realizado por Camelo e Angerami (2008), que buscou identificar e analisar estratégias utilizadas pelos trabalhadores para gerenciar os riscos psicossociais presentes no ambiente do trabalho, a religião foi referenciada pelos ACS como uma estratégia para aliviar as tensões. 0 resultado apresentado na EMEP, utilizada neste estudo, revelou que os ACS tendem a acreditar que ações religiosas ou místicas poderiam auxiliar no afastamento do problema da mente, os pensamentos estariam voltados para a fé e permeados por sentimentos de esperança.

Resultado semelhante foi obtido em estudo realizado por Seidl e Faria (2006), ao analisar as estratégias de enfrentamento de pacientes portadores do vírus HIV, que constatou que os participantes utilizavam mais estratégias cognitivas e comportamentais direcionadas ao manejo do problema, e menos estratégias focalizadas na emoção.
Quanto à estratégia busca de suporte social, que aparece no terceiro posto, ela visa à busca de apoio instrumental, emocional ou de informações (Seidl e col., 2001).

Combinando-se os resultados obtidos por meio do MBI e do EMEP verificou-se, nessa amostra de ACS, que eles seguem a lógica da sequência de desenvolvimento da síndrome em que a despersonalização aparece com menor valor. Segundo a teoria, quando há resultados altos nesse domínio a síndrome está instalada. Embora tenham respondido, quando indagados sobre os aspectos positivos e negativos de seu trabalho, que o próprio trabalho é um aspecto positivo, indicando sua valorização, ao responderem ao instrumento mostram insatisfação com seu desempenho no trabalho, possivelmente por terem colocado nele expectativas altas de efetividade. Verificou-se, então, um grau de sofrimento nesse quesito que precisa ser ajustado para que gere menos insatisfação.

A dinâmica de emprego das estratégias de enfrentamento, por seu turno, mostra que há uma racionalidade presente, pois os ACS mostraram utilizar estratégias focalizadas no problema e de busca de apoio social de modo mais frequente. As estratégias focalizadas no pensamento religioso e na emoção foram menos utilizadas. Dessa forma, embora pouco satisfeitos e realizados com seu trabalho, os ACS reconhecem sua importância e parecem estar empreendendo esforços no sentido de se preservarem para lidar de forma efetiva com o cotidiano de sua atuação profissional.

Embora limitado a uma amostra do contingente de ACS de um município, conclui-se que este trabalho permitiu mostrar aspectos importantes da relação profissional e trabalho, especialmente neste caso em que o profissional tem na relação de ajuda e cuidado sua principal atribuição.

\section{Referências}

ALMEIDA FILHO, N.; ROUQUARYOL, M. Z. Introdução à epidemiologia moderna. Belo Horizonte: CCOPMED; Salvador: APCE; Rio de Janeiro: Abrasco; 1992.

ALVAREZ, E.; FERNANDEZ, L. El Síndrome de Burnout: o el desgaste profesional (I e II). Revista de la Asociación Española de Neuropsiquiatria, La Coruña, v. 11, n. 39, p. 257-65, 1991. 
AMORIM, O. Pedagogia clinica: notas e comentários. Belo Horizonte: Instituto Félix Guatarri; 2002.

BARBANTI, E. J. Exercício físico e saúde.

jun. 2008. Disponível em: <http://

exerciciosdependentesquimicosedepress.blogspot. com/2008/o6/exerccio-fsico-sade.html >. Acesso em: o6 jun. 2008.

BENEVIDES-PEREIRA, A. M. T. Burnout: quando o trabalho ameaça o bem estar do trabalhador. 2. ed. São Paulo: Casa do Psicólogo; 2003 a.

BENEVIDES-PEREIRA, A. M. T. O estado da arte do Burnout no Brasil. Revista Eletrônica InterAção Psy, Maringá, v. 1, n.1, p. 4-11, ago. 2003b.

BENEVIDES-PEREIRA, A. M. T.; MORENO-JIMENEZ, B. O Burnout e o profissional de psicologia. Revista Eletrônica InterAção Psy, v. 1, n. 1, p. 68-75, ago. 2003.

BEZERRA, A. F. B.; ESPIRITO SANTO, A. C. G.;

BATISTA FILHO, M. Concepções e práticas do agente comunitário na atenção à saúde do idoso. Revista de Saúde Pública, São Paulo, v. 39, n. 5, p. 8o9-15, out. 2005 .

BRANDEN, N. Auto-estima e os seus seis pilares. 7. ed. São Paulo: Saraiva; 2002.

BRASIL. Decreto $n^{\circ} 3.048$ de o6 de maio de 1999. Aprova o regulamento da Previdência Social, e dá outras providências. Disponível em: <http://www. trto2.gov.br/geral/tribunal2/Legis/Decreto/3048_ 99.htm>. Acesso em: 28 set. 2006.

BRASIL. Ministério da Saúde. Conselho Municipal de Saúde. Comissão Nacional de Ética em Pesquisa - CONEP. Normas para pesquisa envolvendo seres humanos. Brasília: Ministério da Saúde, 200o. 87 p. (Res. CNS 196/96 e outras).

BRASIL. Ministério da Saúde. Secretaria de Políticas de Saúde. Departamento de Atenção Básica. Análise de reestruturação dos modelos assistenciais de saúde em grandes cidades: padrões de custos e forma de financiamento. Brasília: Ministério da Saúde, 2002.

BRASIL. Portaria 648 de 28 de março de 2006. Aprova a política Nacional de Atenção Básica, estabelecendo a revisão de diretrizes e normas para a organização da Atenção Básica para o Programa
Saúde da Família (PSF) e o Programa Agentes Comunitários de Saúde (PACS). Brasília, 28 de março 2006. Disponível em: <http://www.planalto.gov. $\mathrm{br} / \mathrm{sas} /$ PORTARIAS/port20o6/GM/GM-648.htm>. Acesso em: 10 out. 2006.

CAMELO, S. H. H. Sintomas de estresse nos trabalhadores atuantes em cinco núcleos de saúde da família. 2002. 109 f. Dissertação (Mestrado) - Escola de Enfermagem de Ribeirão Preto da Universidade de São Paulo, Ribeirão Preto, 2002.

CAMELO, S. H. H.; ANGERAMI, E. L. S. Estratégias de gerenciamento de riscos psicossociais no trabalho das equipes de saúde da família. Revista Eletrônica de Enfermagem, v. 10, n. 4, p. 915-23. Disponível em: <http: //www.fen.ufg.br/revista/v1o/n4/v1on4ao4. htm>. Acesso em: 7 jan. 2009.

CARLOTTO, M. S.; CÂMARA, S. G. Análise da produção científica sobre a síndrome de burnout no Brasil. PSICO, Porto Alegre, v. 39, n. 2, p. 152-8, abr./ jun. 2008.

CARLOTTO, M. S.; PALAZZO, L. S. Síndrome de burnout e fatores associados: um estudo epidemiológico com professores. Cadernos de Saúde Pública, Rio de Janeiro, v. 22, n. 5, p. 1017-26, maio 2006.

CODO, W. (Coord.). Educação, carinho e trabalho: Burnout, a síndrome da desistência do educador, que pode levar à falência da educação. Petrópolis: Vozes; 2002.

CODO, W.; VASQUES-MENEZES, I. Burnout: sofrimento psíquico dos trabalhadores em educação. São Paulo: Kingraf; 2000.

DEJOURS, C. A loucura do trabalho: estudo de psicopatologia do trabalho. 3. ed. São Paulo: Cortez/ Oboré; 1988.

FERRAZ, L.; AERTS, D. R. G. C. O cotidiano de trabalho do agente comunitário de saúde no PSF em Porto Alegre. Ciência \& Saúde Coletiva, Rio de Janeiro, v. 10, n. 2, abr. 2005. Disponível em: <http://www.scielo.br/scielo.php?script=sci_ arttext\&pid=S1413-81232005000200012\&lng=pt\&nr m=iso>. Acesso em: 12 fev. 2009. FOLKMAN, S. et al. Appraisal, coping, health status and psychological symptoms. Journal of Personality and Social Psychology, Lisboa, v. 5o, n. 3, p. 571-9, Mar. 1986. 
GIL-MONTE, P.; PEIRÓ, J. M. Desgaste psíquico en el trabajo: el síndrome de quemarse. Madri: Síntesis; 1997.

KANAANE, R. Comportamento humano nas organizações: o homem rumo ao Século XXI. São Paulo: Atlas; 1994.

KLUTHCOVSKY, A. C. G. C. Qualidade de vida dos agentes comunitários de saúde de um município do interior do Paraná. 2005. 118 f. Dissertação (Mestrado) - Escola de Enfermagem de Ribeirão Preto da Universidade de São Paulo, Ribeirão Preto, 2005 .

LUNARDELO, S. R. O trabalho do agente comunitário de saúde nos núcleos de saúde da família em Ribeirão Preto. 2004. 154 f. Dissertação (Mestrado)

- Escola de Enfermagem de Ribeirão Preto da Universidade de São Paulo, Ribeirão Preto, 2004.

MASLACH, C.; LEITER, M. Trabalho: fonte de prazer ou desgaste? Guia para conhecer o estresse na empresa. Campinas: Papirus; 1999.

MASLACH, C.; SCHAUFELI, W. B.; LEITER, M. Job burnout. Annual Review of Psychology, Washington, v. 52, p. 397-422, 2001.

PEREIRA, M. G. Epidemiologia: teoria e prática. Rio de Janeiro: Guanabara Koogan, 1995.

SANTOS, O. A. S. G.; CHAMON, E. M. Q. O. Estresse e estratégias de enfrentamento: um estudo de caso no setor socioprodutivo. In: ENCONTRO LATINO AMERICANO DE INICIAÇÃO CIENTÍFICA, 10. e ENCONTRO LATINO AMERICANO DE PÓSGRADUAÇÃO, 6., 2006, Universidade do Vale do Paraíba. Disponível em: <http://www.inicepg.univap. br/INIC_20o6/epg/o6/EPGooooo370_ok.pdf>. Acesso em: 6 dez. 2008.

SAVÓIA, M. G.; SANTANA, P. R.; MEJIAS, N. P. Adaptação do inventário de estratégias de coping de Folkman e Lazarus para o português. Psicologia USP, São Paulo, v. 7, n 1/2, p.183-201, 1996.
SEIDL, E. M. F.; FARIA, J. B. Religiosidade, enfrentamento e bem-estar subjetivo em pessoas vivendo com HIV/AIDS. Psicologia em Estudo, Maringá, v. 11, n. 1, p. 155-164, jan./abr. 2006. SEIDL, E. M. F.; TROCCOLI, B. T.; ZANNON, C. M. L. C. Análise fatorial de uma medida de estratégia de enfrentamento. Psicologia: Teoria e Pesquisa, Brasília, v. 17, n. 3, p. 225-34, set.-dez. 2001.

SILVA, F. P. P. Burnout: um desafio à saúde do trabalhador. Psicologia, Londrina, v. 2, n. 1, 2000. Disponível em: <http://www2.uel.br/ccb/psicologia/ revista/textov2n15.htm>. Acesso em: 10 jan. 2007.

SILVA, W. R.; BARBOZA, D. M. A síndrome de burnout em professores da Universidade Federal de Sergipe. In: CONGRESSO NORTE-NORDESTE DE PSICOLOGIA, 3., 2003, João Pessoa. Anais... João Pessoa: UFPB/CRP-13, 2003. v. 1, p. 393-4.

SILVA, J. I. A.; DALMASO, A. S. W. Agente comunitário de saúde: o ser, o saber, o fazer. Rio de Janeiro: Fiocruz, 2002. 240 p.

SIMÕES, A. F. Influência da atividade física no tratamento da osteoporose. 2008. Disponível em: <http://www.cdof.com.br/fisio5.htm>. Acesso em: 8 fev. 2008.

TAMAYO, M. R. Relação entre a síndrome de Burnout e os valores organizacionais no pessoal de enfermagem de dois hospitais públicos. Dissertação (Mestrado) - Universidade de Brasília, Brasília, 1997. [não publicada].

WAI, M. F. P. O trabalho do agente comunitário de saúde na estratégias de saúde da família: fatores de sobrecarga e mecanismos de enfrentamento. 2007. 137 f. Dissertação (Mestrado) - Escola de Enfermagem de Ribeirão Preto da Universidade de São Paulo, Ribeirão Preto, 2007.

ZAKIR, N. S. Mecanismos de Coping. In: LIPP, M. E. N. (Org.) Mecanismos neuropsicofisiológicos do stress: teoria e aplicações clínicas. São Paulo: Casa do Psicólogo; 2003. p. 93-8.

Recebido em: 16/07/2008

Reapresentado em: 27/02/2009

Aprovado em: 14/04/2009 